Article

\title{
Experimental Study on the Air Concentration Distribution of Aerated Jet Flows in a Plunge Pool
}

\author{
Weilin $\mathrm{Xu}{ }^{*}$, Chunqi Chen and Wangru Wei \\ State Key Laboratory of Hydraulics and Mountain River Engineering, Sichuan University, \\ Chengdu 610065, China; ccq-cedric@163.com (C.C.); wangru_wei@hotmail.com (W.W.) \\ * Correspondence: xuwl@scu.edu.cn
}

Received: 20 October 2018; Accepted: 30 November 2018; Published: 4 December 2018

\begin{abstract}
There is a lack of knowledge on the air concentration distribution in plunge pools affected by aerated jets. A set of physical experiments was performed on vertical submerged aerated jet flows impinging a plunge pool. The air concentration distribution in the plunge pool was analyzed under different inflow air concentrations, flow velocities, and discharge rate conditions. The experimental results show that the air concentration distribution follows a power-law along the jet axis, and it is independent of the initial flow conditions. A new hypothetical analysis model was proposed for air diffusion in the plunge pool, that is, the air concentration distribution in the plunge pool is superposed by the lateral diffusion of three stages of the aerated jet motion. A set of formulas was proposed to predict the air concentration distribution in the plunge pool, the results of which showed good agreement with the experimental data.
\end{abstract}

Keywords: submerged jets; aerated flow; air concentration; plunge pool

\section{Introduction}

The impingement of a jet flow on a floor is a common issue that is important for many engineering applications, such as the flood discharging of hydraulic structures, and heat and mass transfer in industrial operations. Due to the presence of the floor being located at a distance from the nozzle exit, the diffusion of jets in a plunge pool is different from that of submerged free jets. Based on how the jet impacts the floor, the flow field can be divided into the free jet region, the impingement region, and the free shear region. The jet flow velocity conforms to the distribution law of submerged free jets in the free jet region. In the impingement region, the jet flow velocity decreases rapidly and reaches zero at the stagnation point $[1,2]$.

Aerated and non-aerated impinging jet flows have been studied by many associated investigators [3-5]. Ervine summarized the characteristics of free turbulent jets, and compared the jet diffusion in the plunge pool with submerged and impinging jets [6]. Ervine collected data for both mean and fluctuating components of the pressure field on a plunge pool floor subjected to jet impingement, and compared the data for circular jets with those for wide rectangular nappes and rectangular slot jets [7]. Castillo analyzed the degree of break-up of a rectangular jet before entering the basin, and its relationship to the pressure fluctuation on the plunge pool floor [8]. Chanson discussed the characteristics and similitude of the air-water flow caused by impinging jets [9]. Wei analyzed the influence of aeration and initial water thickness on the axial velocity attenuation of jet flows using experiments and numerical calculations $[10,11]$. The research concludes that increasing the air concentration of jet flows and decreasing the initial jet thickness are effective ways to improve the axial velocity attenuation of jet flows. Some researchers focused on the pressure on the floor of the plunge pool by an aerated and non-aerated jet flow [12-15]. The results showed that the decreasing effect of air concentration on the time-averaged impact pressure is minimal, if any. However, 
the fluctuating pressure rises as the air concentration increases. Duarte compared the jet impingement on the center and side of a block embedded on the floor using plunging and submerged jets $[16,17]$. Others have inquired into the scouring of the plunge pool floor due to jets [18-20]. In addition to the velocity and pressure fields in the plunge pool, the process of air bubble entrainment at the impinging point of the water surface has also been studied extensively [21,22]. From the interaction of the jet flow and the plunge pool surface, an air sheet forms around the impinging point before air bubbles are entrained into the water surface [23]. Several correlative and predictive models on the air entrainment ratio have been reported, due to plunging jets under different working conditions [24-26]. Some researchers used numerical simulations to study aerated jet flows. Brouillio performed a series of two-dimensional numerical experiments on a translating impacting jet, and studied the dynamics of air entrainment by the jets impacting on the surface of the water [27]. Samanta studied the effect of the permeable wall on secondary cross-stream flow by performing direct numerical simulations of the fully developed turbulent flow through a porous square duct [28]. In model tests, the jet velocity profiles and pressure fluctuations on the plunge floor have been studied extensively, with detailed results available. Numerical simulations can essentially reflect characteristics such as the flow field and air entrainment process on the water surface. However, for mass and heat transfer characteristics at the air-water interface under complex conditions, a large number of systematic tests are still needed.

Few researchers have studied the air concentration distribution in the entire plunge pool, including the free shear region. Dong described the concentration diffusion of an aerated jet in the plunge pool with different plunging angles [29]. The air concentration along the jet axis gradually decreased, following a hyperbolic curve. Chanson conducted separate experiments with a vertical supported jet and a horizontal hydraulic jump [30]. The results showed that the air concentration in both cases exhibits a Gaussian distribution, and the longitudinal maximum air content declines exponentially. Khaled used the Particle Image Velocimetry (PIV) technique to characterize the flow field of both aerated and non-aerated jet flows beneath the water surface [31]. However, analyses and predictions of air concentration distribution in the entire plunge pool, especially where affected by the swirling jet, are still missing.

In the present paper, measurements and analyses of the air concentration distribution are presented for a plunge pool. A new analysis model is proposed to describe the air diffusion, with jet swirling in the entire plunge pool. A set of formulas has been built up to predict the air concentration distribution, and the results are believed to be useful for understanding and predicting the air concentration distribution in both the plunge pool and downstream.

\section{Experimental Methods}

Experiments were carried out at the State Key Laboratory of Hydraulics and Mountain River Engineering (Sichuan University). An experimental facility was set up, as shown in Figure 1. The jet was aerated before being plunged vertically into the still water in a rectangular glass flume of $4.00 \mathrm{~m}$ $\times 0.25 \mathrm{~m} \times 0.80 \mathrm{~m}$. The airflow was provided using an air compressor with a power rating of $7.5 \mathrm{~kW}$ at a pressure of $0.8 \mathrm{MPa}$. The inflow jet was controlled using valves and measured with a TDS- $100 \mathrm{H}$ ultrasonic flowmeter, of which the measurement range was $0.8-128.0 \mathrm{~L} / \mathrm{s}$, and the relative error of measurement was $\pm 1 \%$. The air was controlled using valves, and measured with a SLDLB-Y150D vortex flowmeter, of which the measurement range was 2.0-60.0 L/s, and the relative error of measurement was $\pm 1 \%$. To form a stable and well-mixed air-water flow, the air was forced through micro-perforated plates with a diameter of $1 \mathrm{~mm}$, and mixed into the water flow in the air entrainment region. The water in the flume flowed out at both ends, where the water level was maintained at $H=0.55 \mathrm{~m}$. The incident angle of the jet flow was 90 degrees. The rectangular nozzle, $0.20 \mathrm{~m}$ in width and $0.02 \mathrm{~m}-0.05 \mathrm{~m}$ at the opening, was installed slightly below the water surface to ensure a precise, stable initial air concentration. 


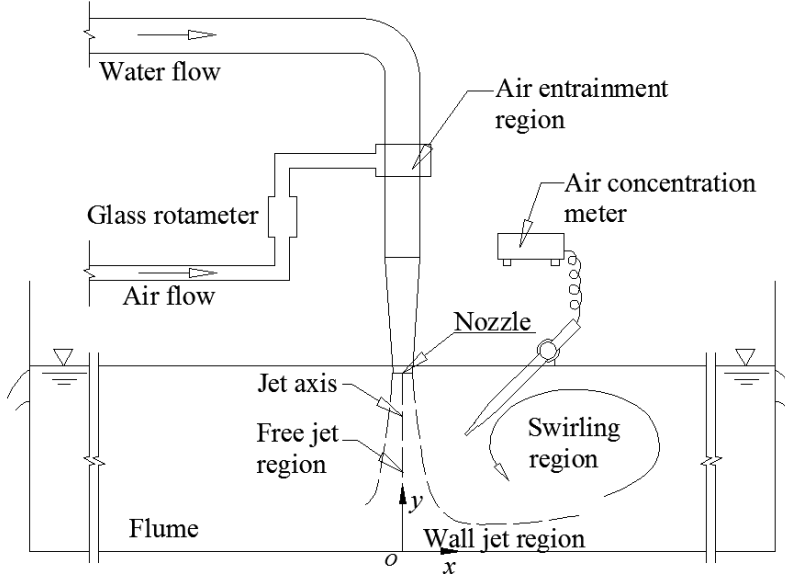

(a) Sketch map

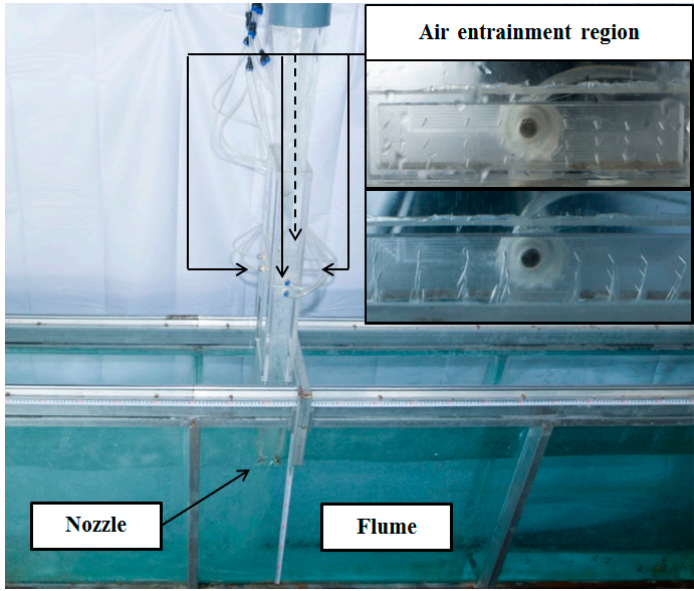

(b) Photograph

Figure 1. Experimental facility.

The coordinate origin of an $x-0-y$ coordinate system was located on the flume floor, the horizontal $x$-axis faced the downstream direction of the plunge pool, and the vertical $y$-axis coincided with the jet axis. In total, there were 264 measurable points for the air concentration in the plunge. A total of 22 rows were arranged along the x-axis direction. First, six rows were set at an interval of $5 \mathrm{~cm}$ $(0 \mathrm{~cm} \leq x \leq 25 \mathrm{~cm})$, and the following 16 rows were set at an interval of $10 \mathrm{~cm}(30 \mathrm{~cm} \leq x \leq 180 \mathrm{~cm})$. In total, 12 rows of measuring points were arranged along the $y$-axis direction, with the first row at $y=1 \mathrm{~cm}$ and the last row at $y=54 \mathrm{~cm}(1 \mathrm{~cm}$ from the flume floor). The remaining 10 rows of measuring points along the $y$-axis were set between $y=5 \mathrm{~cm}$ and $y=50 \mathrm{~cm}$ at intervals of $5 \mathrm{~cm}$. The air concentration was tested using a CQ6-2004 resistance-type air concentration meter (China Institute of Water Resources and Hydropower Research) with a resolution of $1 \%$. The measurement principle of the resistance-type air concentration meter was to determine the air concentration by detecting the clear water resistance and the aerated water resistance between the two electrodes, and averaging the air concentration values in the selected integration time. Accurate flow measurements can be an important factor in obtaining adequate conclusions [32]. Different integration times for the air concentration measurements were tested beforehand, as shown in Figure 2. It can be seen that the mean air concentration data fall in the measurement accuracy zone if the integration time of the air concentration meter exceeds 60 seconds. Therefore, the sampling period for each measurement point was set to 60 seconds to minimize random error.

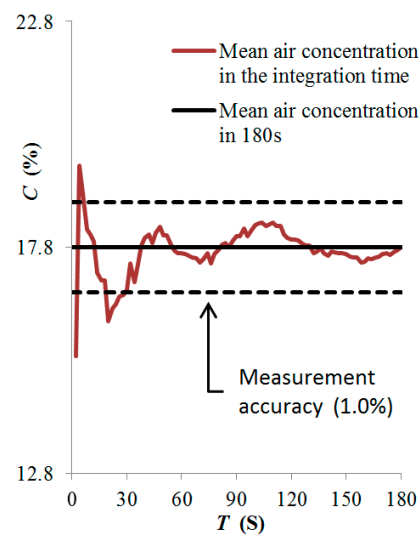

(a)

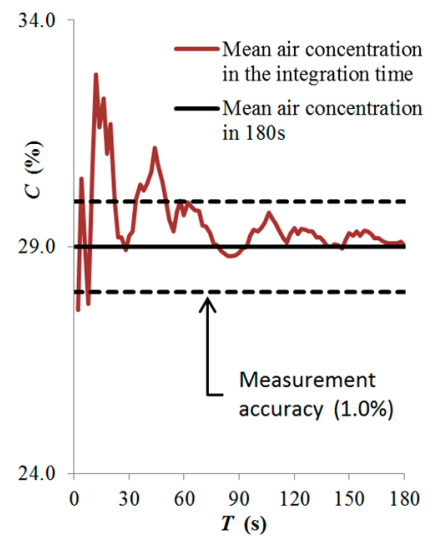

(b)

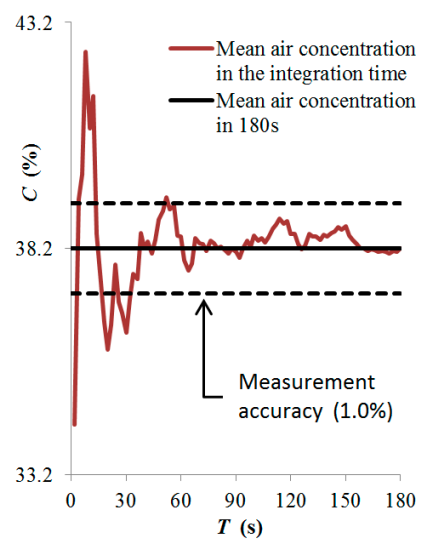

(c)

Figure 2. The uncertainty of air concentration measurements in the plunge pool. 
The experiments were performed under different conditions, including the jet flow thickness $d_{0}$ $(2 \mathrm{~cm}, 3 \mathrm{~cm}, 4 \mathrm{~cm}, 5 \mathrm{~cm})$, the initial air concentration $C_{0}(10 \%, 15 \%, 30 \%, 40 \%, 50 \%, 60 \%)$, the clear water flow rate $Q_{\mathrm{w}}(14.0 \mathrm{~L} / \mathrm{s}-35.2 \mathrm{~L} / \mathrm{s})$, and the air flow rate $Q_{\mathrm{a}}(2.1 \mathrm{~L} / \mathrm{s}-42.0 \mathrm{~L} / \mathrm{s})$, as listed in Table 1 .

Table 1. Experimental conditions.

\begin{tabular}{cccccccc}
\hline No. & $\boldsymbol{d}_{\mathbf{0}} \mathbf{( \mathbf { c m } )}$ & $\boldsymbol{C}_{\mathbf{0}} \mathbf{( \% )}$ & $\boldsymbol{Q}_{\mathbf{w}}(\mathbf{L} / \mathbf{s})$ & $\mathbf{N o}$. & $\boldsymbol{d}_{\mathbf{0}} \mathbf{( \mathbf { c m } )}$ & $\boldsymbol{C}_{\mathbf{0}} \mathbf{( \% )}$ & $Q_{\mathbf{w}}(\mathrm{L} / \mathbf{s})$ \\
\hline 1 & 2 & 10 & 18.6 & 16 & 3 & 30 & 21.1 \\
2 & 2 & 15 & 16.1 & 17 & 3 & 40 & 21.1 \\
3 & 2 & 30 & 14.0 & 18 & 3 & 40 & 23.9 \\
4 & 2 & 30 & 16.8 & 19 & 3 & 50 & 23.9 \\
5 & 2 & 30 & 19.6 & 20 & 4 & 15 & 27.8 \\
6 & 2 & 30 & 22.4 & 21 & 4 & 30 & 21.1 \\
7 & 2 & 40 & 16.7 & 22 & 4 & 30 & 28.2 \\
8 & 2 & 50 & 14.7 & 23 & 4 & 40 & 28.2 \\
9 & 2 & 60 & 14.5 & 24 & 4 & 50 & 21.1 \\
10 & 2.3 & 10 & 21.1 & 25 & 4 & 50 & 23.9 \\
11 & 2.3 & 15 & 23.9 & 26 & 4 & 50 & 27.8 \\
12 & 2.5 & 15 & 21.1 & 27 & 5 & 30 & 35.2 \\
13 & 2.5 & 30 & 21.1 & 28 & 5 & 30 & 21.1 \\
14 & 3 & 10 & 21.3 & 29 & 5 & 40 & 35.2 \\
15 & 3 & 15 & 21.1 & 30 & 5 & 50 & 23.9 \\
\hline
\end{tabular}

In the experiment, the aerated jet was vertically injected and outflowed simultaneously at both ends of the flume, which was slightly wider than the nozzle exit. Jets could develop on the bottom plate of the flume under all experimental conditions. Thus, the development of the aerated jet in the plunge pool could be simplified as a two-dimensional flow, which is symmetrical to the jet axis ( $y$-axis). For typical working conditions $\left(d_{0}=2 \mathrm{~cm}, C_{0}=30 \%, Q_{\mathrm{w}}=16.8 \mathrm{~L} / \mathrm{s}\right)$, an experimental photograph and a contour map of the air concentration distribution on one side of the jet axis are shown in Figure 3. The majority of the air bubbles flow with the jet flow in the free jet region, before being blocked by the flume floor and deflected by 90 degrees into the wall jet region on both sides. Afterwards, the air bubbles flow gradually towards the water surface, with some eventually escaping into the surrounding air, whereas the rest are carried into the swirling region.

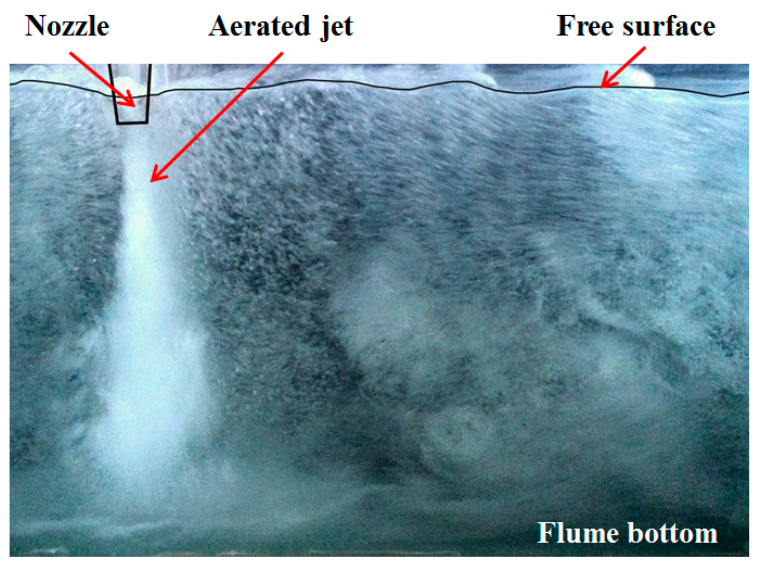

(a) Photograph

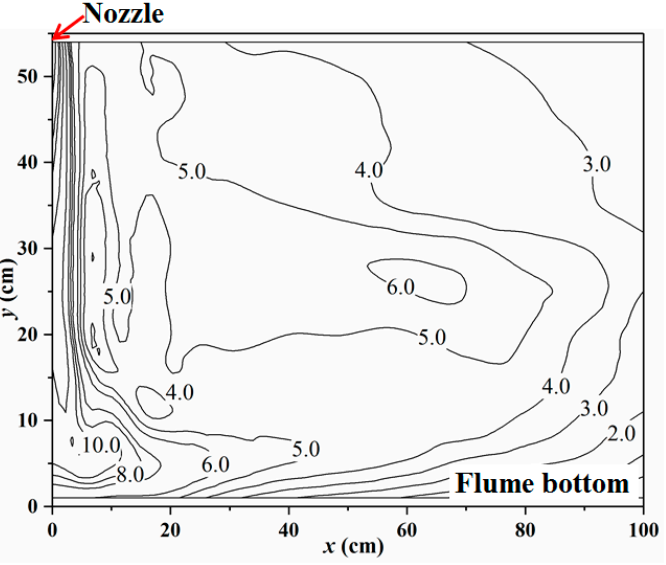

(b) Air concentration contour map

Figure 3. Air concentration distribution for $d_{0}=2 \mathrm{~cm}, C_{0}=30 \%, Q_{\mathrm{w}}=16.8 \mathrm{~L} / \mathrm{s}$. 


\section{Results and Discussion}

\subsection{Air Concentration Distribution in the Free Jet Region}

Along the jet axis, the air concentration distribution should be closely related to the jet velocity distribution. The jet velocity decreases sharply as the aerated jet approaches the plunge pool floor. Due to the pressure gradient, the jet carrying air bubbles drifts toward both sides of the plunge pool, resulting in a steep decrease in air concentration in the impingement region. The region higher than one-fifth of the water depth is considered to be the free jet region, where the attenuation of air concentration was studied in the test.

Considering the influencing factors, the initial water velocity $V_{\mathrm{w}}$, the initial air concentration $C_{0}$, and the clear water flow rate $Q_{\mathrm{w}}$ were adopted, and a series of experiments were performed to test each effect on the air concentration attenuation, as shown in Figure 4. Under a different initial water velocity $\left(3 \mathrm{~m} / \mathrm{s}<V_{\mathrm{w}}<8 \mathrm{~m} / \mathrm{s}\right)$ and a clear water flow rate $\left(21.1 \mathrm{~L} / \mathrm{s}<Q_{\mathrm{w}}<35.2 \mathrm{~L} / \mathrm{s}\right)$, the attenuation of $C_{\mathrm{m}} / C_{0}$ varies in a similar pattern along the jet axis. The reason for the results is that the velocity attenuation along the jet axis changes little with different flow conditions, including the initial jet velocity and the clear water flow rate [33].

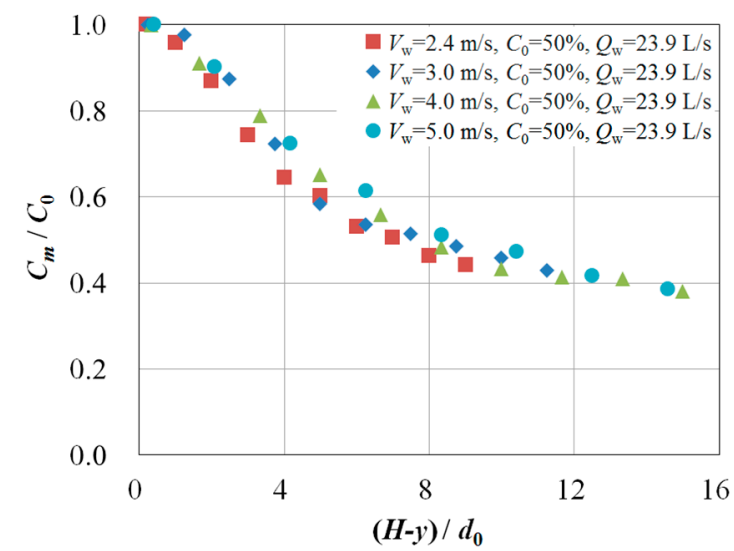

(a) Air concentration distribution for different $V_{\mathrm{w}}$

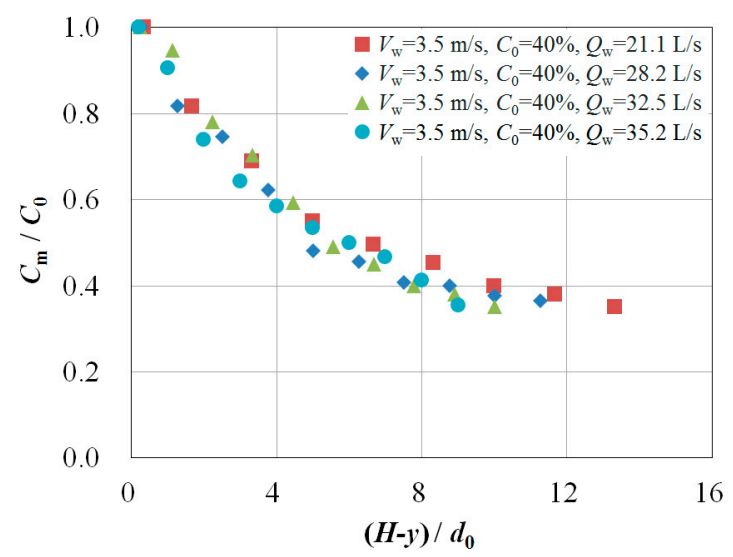

(b) Air concentration distribution for different $Q_{w}$

Figure 4. Influence of $V_{\mathrm{w}}$ and $Q_{\mathrm{w}}$ on axial air concentration distribution.

By theoretically analyzing the concentration flux of the aerated jet based on the self-similarity of the velocity and air concentration distribution, the power-law relation was found between the axial air concentration and the flow distance in the free jet region [29]. The relationship between the axial air concentration $C_{m}$ and the distance from the nozzle $x^{\prime}=H-y$, normalized by the initial air concentration $C_{0}$ and the jet flow thickness $d_{0}$ in the plunge pool, respectively, is written as:

$$
\frac{C_{\mathrm{m}}}{C_{0}}=k_{0} \times\left(\frac{x^{\prime}}{d_{0}}\right)^{-0.5}=k_{0} \times \sqrt{\frac{d_{0}}{H-y}}
$$

where $k_{0}$ is a coefficient, suggested as approximate 1.2 in this study.

The calculated results of the axial air concentration distribution in the free jet region using Equation (1) was compared with the experimental data, as shown in Figure 5a. Independent of the initial jet velocity and the clear water flow rate, the axial air concentration sharply decreased to about $50 \%$ of $C_{0}$ in a short distance $\left(\frac{H-y}{d_{0}} \approx 5\right)$ from the nozzle exit. Due to the influence of the pressure gradient near the plunge floor, further from the nozzle exit, the air concentration distribution was more dispersed in the free jet region. It can be derived from the experimental results that the air concentration distribution along lateral cross-sections in the free jet region conformed to the Gaussian distribution law, as shown in Figure $5 b$. In the free jet region, no significant influence of different initial flow conditions was observed on the cross-sectional air concentration distribution, which tended to be 
self-similar. Downstream of the free jet region, the cross-sectional air concentration distribution was affected by the swirling jet in the plunge pool.

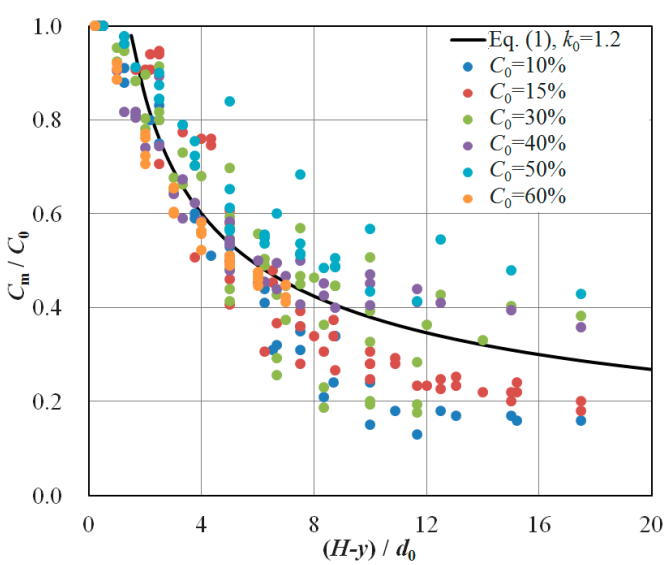

(a) Axial air concentration distribution

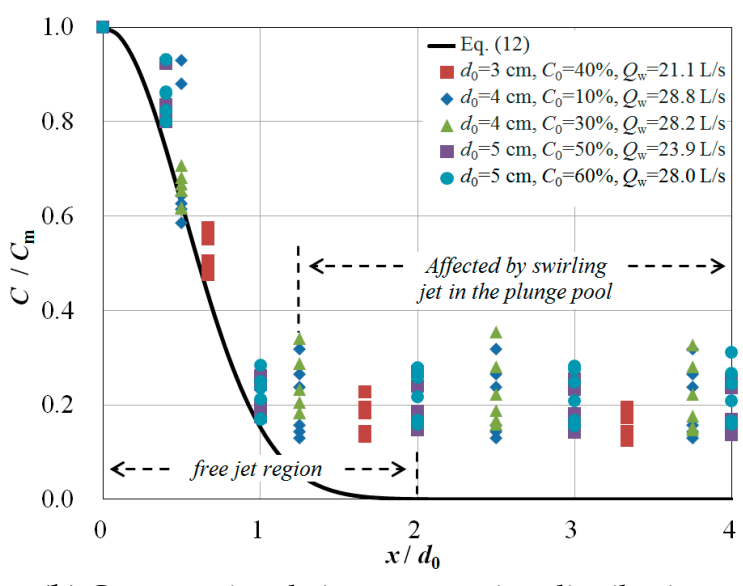

(b) Cross-sectional air concentration distribution

Figure 5. Air concentration distribution in the free jet region.

For a two-dimensional constant jet along the $x^{\prime}$ direction in an $x^{\prime}-0-y^{\prime}$ coordinate system, the continuity equation of the air concentration diffusion is:

$$
\frac{\partial(C U)}{\partial x^{\prime}}+\frac{\partial(C V)}{\partial y^{\prime}}=\frac{\partial}{\partial y^{\prime}}\left(D_{y} \frac{\partial C}{\partial y^{\prime}}\right)
$$

where $C$ is the air concentration, $U$ is the velocity in the $x^{\prime}$ direction, $V$ is the velocity in the $y^{\prime}$ direction, and $D_{y}$ is the turbulent diffusion coefficient.

The longitudinal velocity $U$ can be approximated using the average velocity $\bar{u}$. The transverse velocity can be negligible, i.e., $V \approx 0$.

According to Prandtl's hypothesis of free turbulence theory [34], $D_{y}$ can be approximated as:

$$
D_{y}=k \bar{u} b
$$

where $k$ is the coefficient, and $b$ is the thickness of the jet, which is assumed to expand linearly and can be written as:

$$
b=m x^{\prime}=\tan \theta \times x^{\prime}
$$

where $\theta$ is the diffusion angle.

Previous research suggests that with respect to the conventional diffusion angle (about eight degrees), the diffusion angle of aerated water increases due to the influence of bubbles [10]. Twelve degrees is taken as the diffusion angel in this study.

Due to hardly any influence of initial flow conditions on both the axial attenuation and the lateral distribution of air concentration in the free jet region, it is assumed that the air concentration distribution in the free jet region is self-similar, resembling that in the velocity distribution, which can be written as:

$$
\frac{C}{C_{\mathrm{m}}}=f_{1}(\eta), \quad \eta=\frac{y^{\prime}}{b}
$$

Combining Equations (2), (3) and (5), $\frac{C}{C_{m}}$ can be expressed as:

$$
f_{1}=\frac{C}{C_{m}}=\mathrm{A} \times \exp \left[-\frac{m}{2 k} \times \eta^{2}\right]
$$


where $\mathrm{A}$ is the integral constant and determined by boundary conditions. When $\eta=\frac{y^{\prime}}{b}=0, C=C_{\mathrm{m}}$, $\mathrm{A}=1$, Equation (6) can be rewritten as:

$$
\frac{C}{C_{m}}=\exp \left[-\frac{m}{2 k} \times\left(\frac{y^{\prime}}{b}\right)^{2}\right]
$$

The concentration half-width is defined as:

$$
b_{1 / 2}=\left.y^{\prime}\right|_{c=0.5 C_{m}}
$$

It is assumed that the concentration half-width extends linearly along the path, thus:

$$
b_{1 / 2}=\frac{1}{2} d_{0}+\tan \theta \times x^{\prime}
$$

Combining Equations (7) and (8):

$$
\ln \left(\frac{1}{2}\right)=-\frac{m}{2 k} \times\left(\frac{b_{\frac{1}{2}}}{b}\right)^{2}=-0.693
$$

Considering:

$$
-\frac{m}{2 k} \times\left(\frac{y^{\prime}}{b}\right)^{2}=-\frac{m}{2 k} \times\left(\frac{b_{\frac{1}{2}}}{b}\right)^{2} \times\left(\frac{y^{\prime}}{b_{\frac{1}{2}}}\right)^{2}=-0.693 \times\left(\frac{y^{\prime}}{b_{1 / 2}}\right)^{2}
$$

Combining Equations (7) and (11), the air concentration distribution on the flow cross-section can be calculated by:

$$
\frac{C}{C_{\mathrm{m}}}=\exp \left[-0.693 \times\left(\frac{y^{\prime}}{b_{1 / 2}}\right)^{2}\right]
$$

where $C$ is the transverse air concentration diffusion, $C_{\mathrm{m}}$ is the corresponding air concentration along the jet axis, and $y^{\prime}$ is the transverse distance from the jet axis.

The calculated result of Equation (12) was compared with the experimental results, as shown in Figure $5 \mathrm{~b}$. In the free jet region, the calculated results of the lateral diffusion were essentially consistent with the experimental data. Further away from the axis, due to the influence of the swirling jet, the experimental value of the air concentration was greater than the calculated result obtained using Equation (13). Therefore, the next section will focus on the establishment of an analysis model for air concentration diffusion in the plunge pool.

In the $x-0-y$ coordinate system in this study, the air concentration distribution in the free jet region can be calculated by:

$$
\begin{aligned}
& C=C_{0} \times 1.2 \sqrt{\frac{d_{0}}{x^{\prime}}} \times \exp \left[-0.693\left(\frac{y^{\prime}}{b_{\frac{1}{2}}}\right)^{2}\right] \\
& =C_{0} \times 1.2 \sqrt{\frac{d_{0}}{H-y}} \times \exp \left[-0.693\left(\frac{x}{b_{1 / 2}}\right)^{2}\right]
\end{aligned}
$$

\subsection{Air Concentration Distribution in the Swirling Region of the Plunge Pool}

For one side of the plunge pool, the experimental photographs of the submerged jet motion and air concentration distribution are shown in Figure 6. After being plunged into the still water, the aerated jet moves along the vertical axis, and the aerated wall jet forms after a 90-degree deflection of the jet flow near the flume floor. While the wall jet moves downstream, it is gradually developed toward the free surface under the combined effects of turbulence and buoyancy. Due to the existence of the downstream board, part of the aerated flow moves upstream along the water surface and forms a swirling region in the plunge pool. At the downstream end of the swirling region, the direction of 
the aerated flow movement is almost vertically upward. While moving with the water flow, the air bubbles expand continuously and laterally into the swirling region under the effects of turbulence.

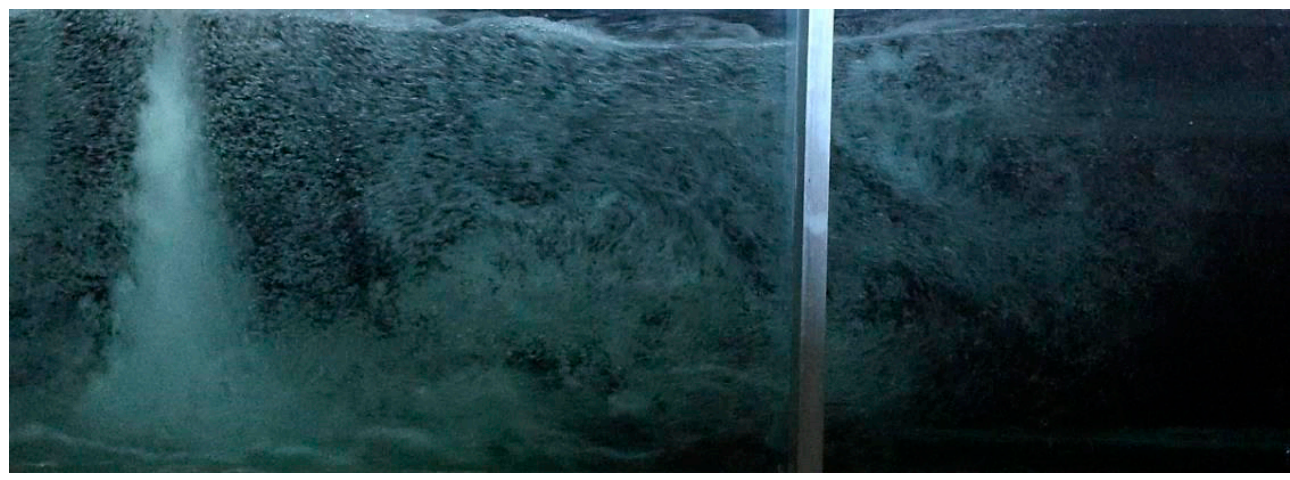

(a) $d_{0}=2 \mathrm{~cm}, C_{0}=15 \%, Q_{\mathrm{w}}=16.1 \mathrm{~L} / \mathrm{s}$

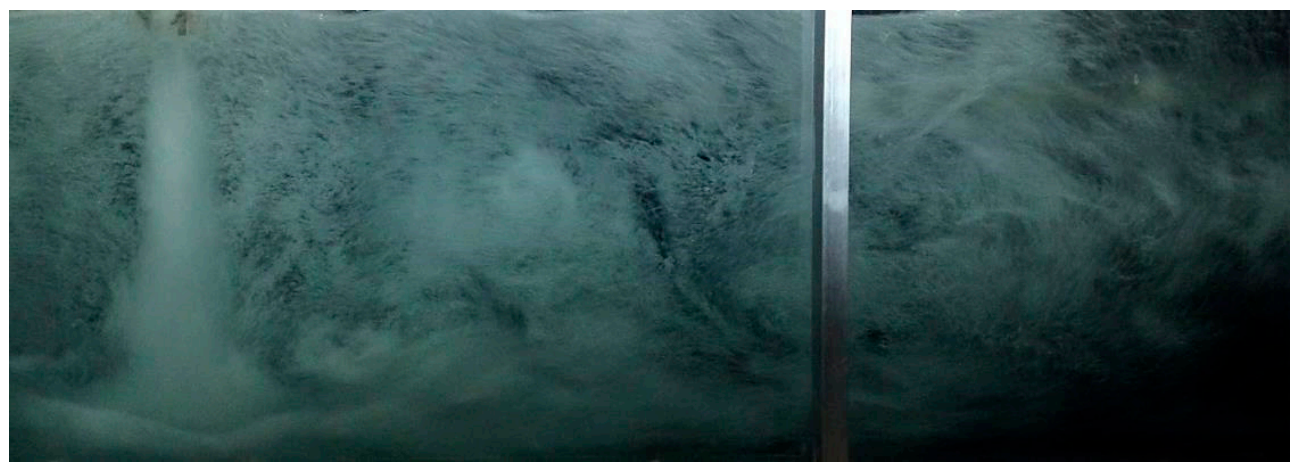

(b) $d_{0}=3 \mathrm{~cm}, C_{0}=30 \%, Q_{\mathrm{w}}=21.1 \mathrm{~L} / \mathrm{s}$

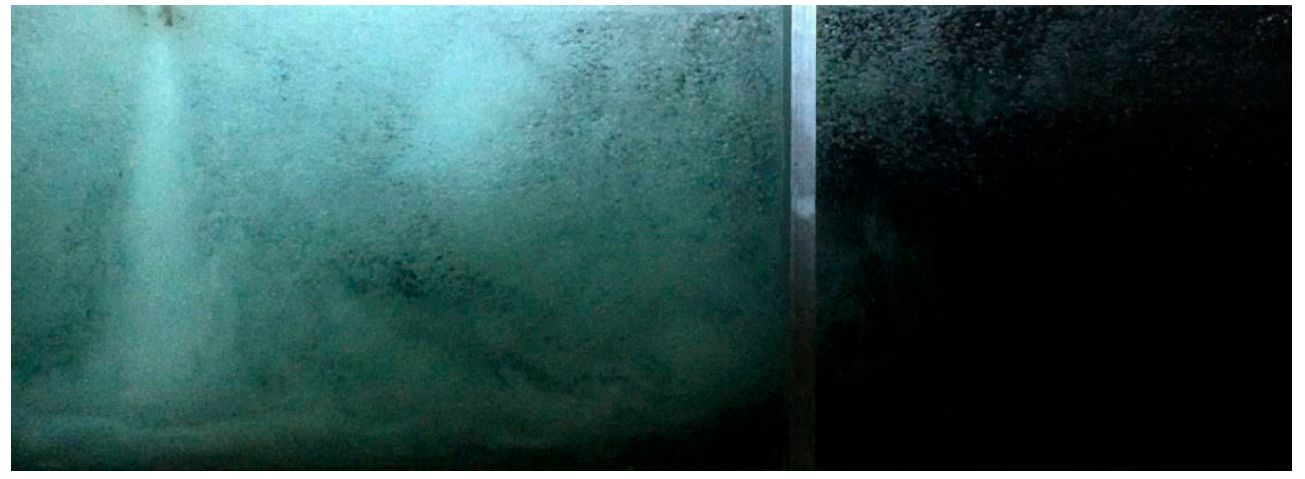

(c) $d_{0}=2 \mathrm{~cm}, C_{0}=60 \%, Q_{\mathrm{w}}=14.5 \mathrm{~L} / \mathrm{s}$

Figure 6. Air concentration distribution in the plunge pool.

According to Melo [13], the flow patterns in the plunge pool impinged by vertical jets are composed of three distinct regions, as shown in Figure 7a. In the free jet region, the vertical jet develops by shearing with the surrounding water body without the influence of the plunge floor. The impact of the jet against the floor builds up the pressure gradient and deflects the jet parallel to the plunge floor into the wall jet region. Due to the limited area of the plunge pool, the horizontal wall jet develops upwards and flows into the swirling region. 


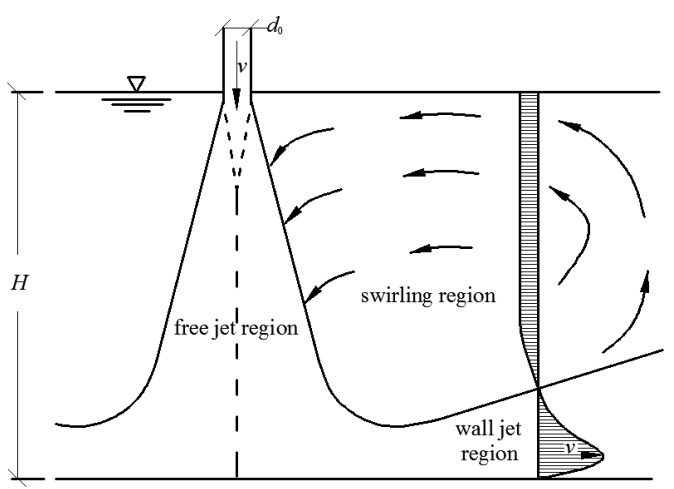

(a) Sketch map of diffusing jet in a pool (Melo [13])

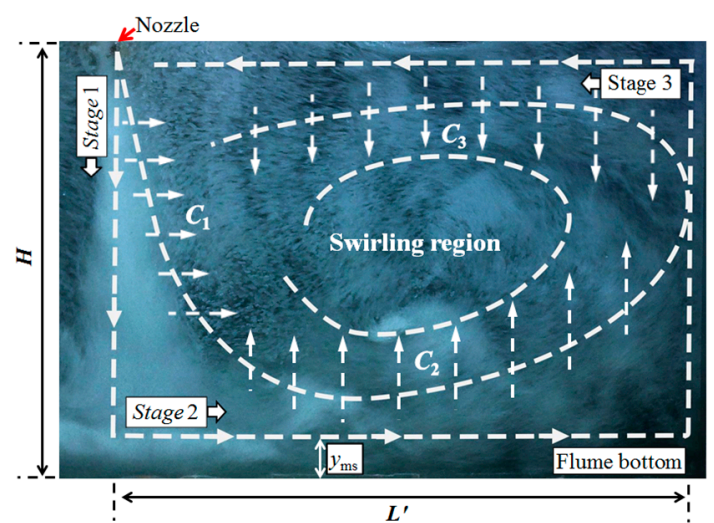

(b) Stages of air concentration diffusion

Figure 7. Generalized calculation of air concentration in the swirling region.

When calculating the concentration field in the swirling region, the motion and diffusion of the air bubbles in the plunge pool are generalized into the following three stages, as shown in Figure 7b:

Stage 1: The aerated jet moves along the jet axis until it reaches the floor of the plunge pool, categorized as the free jet region in Figure 7a. The attenuation and lateral diffusion of the air concentration occurs along the path, which is consistent with the distribution law in the free jet region mentioned above. At this stage, the air concentration that diffuses laterally into the swirling region is taken as $C_{1}$;

Stage 2: The aerated flow is deflected by 90 degrees at the bottom of the plunge pool, and moves along the axis near the bottom plate, categorized as the wall jet region in Figure 7a. Regardless of the local and instantaneous air concentration loss, the initial air concentration at this stage is assumed to be the same as the air concentration at the end of the axis in the previous stage. The air concentration of the aerated jet continues to decrease along the path, until the jet reaches the end section of the swirling region. At this stage, the air concentration that diffuses vertically into the swirling region is taken as $\mathrm{C}_{2}$;

Stage 3: The aerated flow moves upstream along the free surface until it reaches the original jet axis at stage 1, categorized as the swirling region in Figure 7a. The initial air concentration value in this stage is obtained by approximating the axis of the aerated jet in the swirling region to a rectangle with a length of $L^{\prime}$ and a width of $H$. The air concentration that diffuses vertically into the swirling region is taken as $C_{3}$.

In the plunge pool, excluding the jet axis, the air concentration at a certain point can be considered as the superposition of $C_{1}, C_{2}$, and $C_{3}$. When calculating the axial air concentration attenuation and the lateral diffusion in the three stages mentioned using Equation (13), separately, the jet flow distance $x^{\prime}$ and the transverse distance from the axis $y^{\prime}$ can be expressed as:

$$
\begin{gathered}
\text { stage } 1: x_{1}^{\prime}=H-y, \quad y_{1}^{\prime}=x \\
\text { stage } 2: x_{2}^{\prime}=H+x, \quad y_{2}^{\prime}=y \\
\text { stage } 3: x_{3}^{\prime}=2 H+2 L^{\prime}-x, \quad y_{3}^{\prime}=H-y
\end{gathered}
$$

In order to locate the end section in stage 2 of the air concentration diffusion, the swirling region length $L^{\prime}$ is defined as the distance between the jet axis and the vertical cross-section, where the mean air concentration equals $5 \%$ of $C_{0}$.

$$
L^{\prime}=\left.x\right|_{c_{\text {mean }}=0.05 c_{0}}
$$

where $C_{\text {mean }}$ is the mean air concentration. 
Under current experimental conditions, the relationship between the swirling region length and the initial water flow velocity is shown in Figure 8, which can be correlated with the linear function as:

$$
\frac{L^{\prime}}{d_{0}}=8 \times \frac{V_{\mathrm{w}}^{2}}{g H}+11, \quad 0.6<\frac{V_{\mathrm{w}}^{2}}{g H}<6
$$

where $V_{\mathrm{w}}$ is the water velocity, and $g$ is the acceleration of gravity. The correlation coefficient is 0.80 . It should be noted that the length of the swirling region was deliberately defined using the statistical mean air concentration of the vertical cross-section. The swirling region was actually determined by the flow field. In the downstream end of the plunge pool, the decrease in flow velocity led to changes in the following behaviors of the air bubbles. This resulted in the deviation of measurements in the experiment.

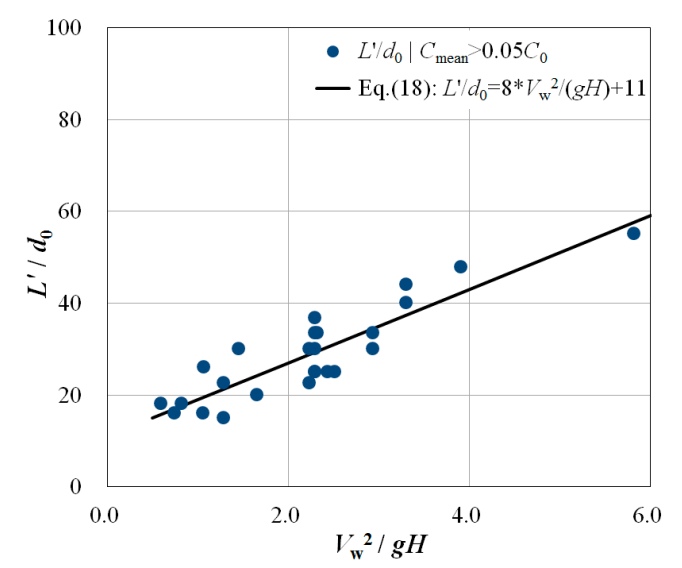

Figure 8. Distribution of swirling region length $L^{\prime}$.

In stage 2 of the air concentration diffusion, the position of the maximum air concentration values along the vertical cross-sections in the wall jet can be estimated as:

$$
y_{\mathrm{ms}}=\frac{1}{3} \times b
$$

where $b$ is the thickness of the jet.

According to Beltaos [35], the relation between the maximum velocity of the wall jet $u_{\mathrm{m} 1}$ and the initial velocity $u_{0}$ is:

$$
\frac{u_{\mathrm{m} 1}}{u_{0}} \sqrt{\frac{H}{d_{0}}}=2.77\left\{1-\exp \left[-38.5\left(\frac{x}{H}\right)^{2}\right]\right\}^{\frac{1}{2}}
$$

Considering the symmetrical aerated flow on both sides of the plunge pool, and the relation:

$$
\frac{1}{2} u_{\mathrm{m} 1} \times b=\frac{1}{2} u_{0} \times d_{0}
$$

Combining Equations (19)-(21), $y_{\mathrm{ms}}$ can be expressed as:

$$
y_{\mathrm{ms}}=\frac{1}{3} \times \frac{\sqrt{H \times d_{0}}}{2.77\left\{1-\exp \left[-38.5(x / H)^{2}\right]\right\}^{1 / 2}}
$$

The air concentration can be linearly solved on the vertical cross-sections between the axis of the wall jet and the plunge pool floor, where the air concentration value is zero. 
According to the above analysis, at any point $(x, y)$ in the swirling region of the plunge pool, the calculation of the lateral air concentration diffusion $C_{1}$ from the jet axis can be written as:

$$
C_{1}=C_{0} \times 1.2 \sqrt{\frac{d_{0}}{H-y}} \times \exp \left[-0.693\left(\frac{x}{b_{1 / 2}}\right)^{2}\right]
$$

The calculation of the vertical air concentration diffusion $C_{2}$ from near the plunge pool floor can be written as:

$$
C_{2}=C_{0} \times 1.2 \sqrt{\frac{d_{0}}{H+x}} \times \exp \left[-0.693\left(\frac{y-y_{\mathrm{ms}}}{b_{1 / 2}}\right)^{2}\right]
$$

The calculation of the vertical air concentration diffusion $C_{3}$ from the free surface can be written as:

$$
C_{3}=C_{0} \times 1.2 \sqrt{\frac{d_{0}}{2 H+2 L^{\prime}-x}} \times \exp \left[-0.693\left(\frac{H-y}{b_{1 / 2}}\right)^{2}\right]
$$

Thus, the air concentration value at the point $(\mathrm{x}, \mathrm{y})$ can be obtained by:

$$
\left.C\right|_{(x, y)}=C_{1}+C_{2}+C_{3}
$$

with 12 degrees of diffusion angles used in calculating $C_{1}$ and $C_{2}$, and zero degrees in calculating $C_{3}$.

Combing Equations (23)-(26), it is possible to calculate the air concentration at any point in the swirling region of the plunge pool.

\subsection{Comparison of Calculated and Experimental Results}

The calculated and experimental results of the air concentration distribution along the vertical cross-sections in the plunge pool are compared in Figure 9. When the initial air concentration was small, such as $C_{0}<40 \%$, the calculated results agreed well with the experimental measurements. When the initial air concentration was large, such as $C_{0}>40 \%$, the calculated results could essentially reflect the variation of the air concentration distribution in the region close to the jet axis, such as $x / d_{0}$ $<15-20$. In the downstream region, on the other hand, such as $x / d_{0}>15-20$, the calculated results were somewhat different from the experimental measurements.

The reason for the deviation is that the bubble motion and diffusion process in the hypothetical analysis model is different from that in the actual jet flow. The influence of the bubble floating process by buoyancy on the actual jet flow was not considered, leading to a decrease in the adaptability of the idealized hypothetical analysis in this paper. However, the absolute value of the air concentration in the downstream region of the plunge pool was relatively small. For example, for $d_{0}=2 \mathrm{~cm}$, $C_{0}=60 \%, Q_{\mathrm{w}}=14.5 \mathrm{~L} / \mathrm{s}$, the absolute value of the air concentration was essentially less than 0.05 in the downstream region, such as $x / d_{0}>10$. Consequently, the present analysis model can essentially predict the air concentration distribution of aerated jet flows in the swirling region of the plunge pool. 


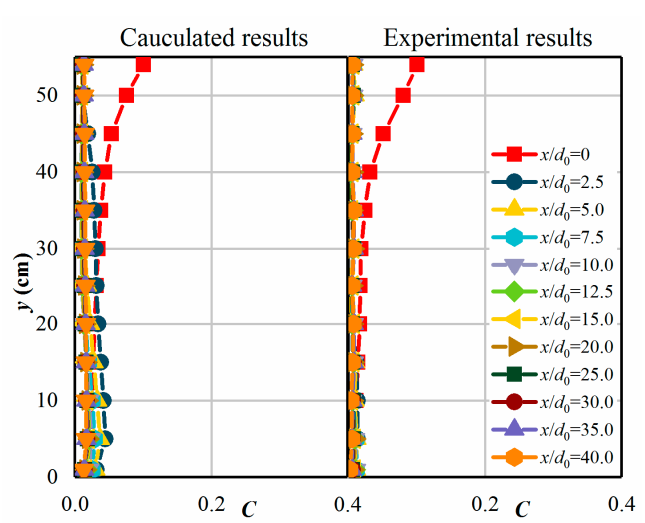

(a) $d_{0}=2 \mathrm{~cm}, C_{0}=10 \%, Q_{w}=18.6 \mathrm{~L} / \mathrm{s}$

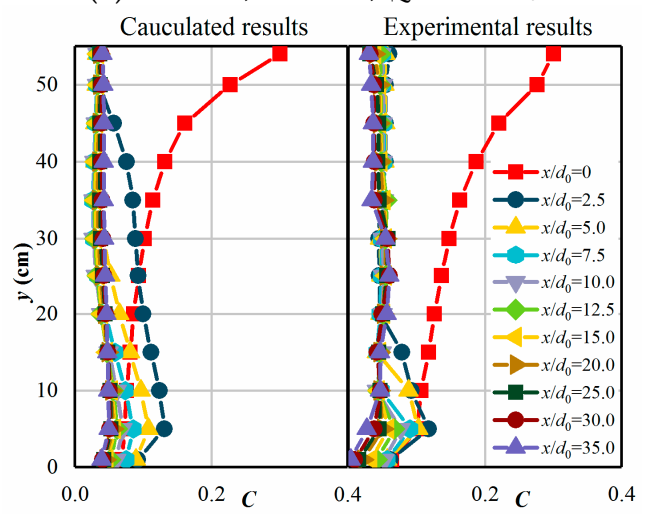

(c) $d_{0}=2 \mathrm{~cm}, C_{0}=30 \%, Q_{\mathrm{w}}=16.8 \mathrm{~L} / \mathrm{s}$

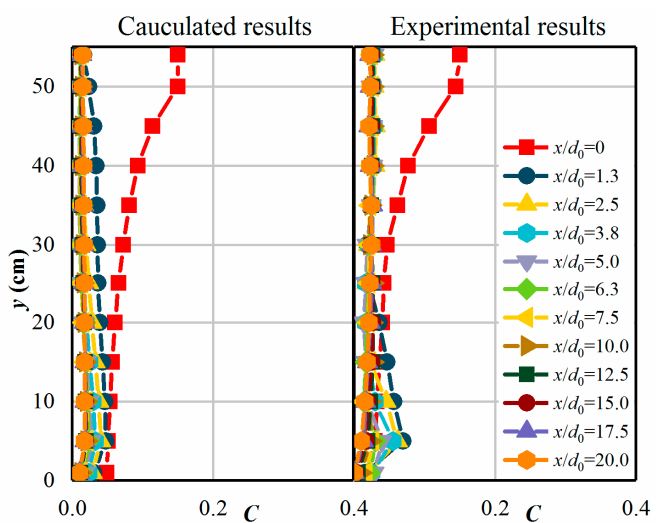

(b) $d_{0}=4 \mathrm{~cm}, C_{0}=15 \%, Q_{\mathrm{w}}=21.1 \mathrm{~L} / \mathrm{s}$

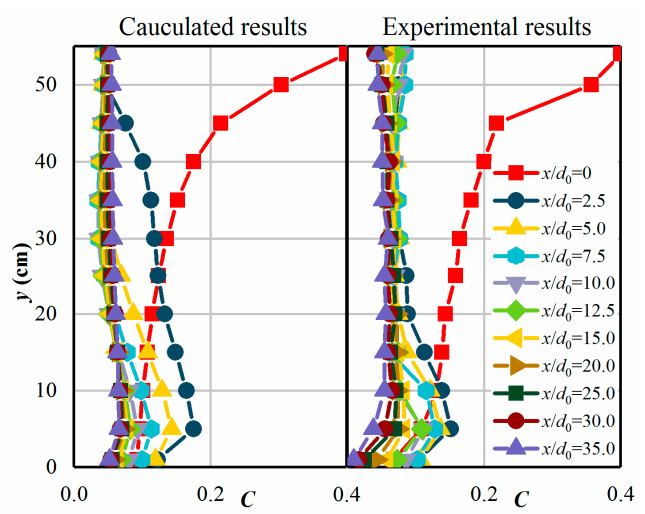

(d) $d_{0}=2 \mathrm{~cm}, C_{0}=40 \%, Q_{\mathrm{w}}=16.7 \mathrm{~L} / \mathrm{s}$

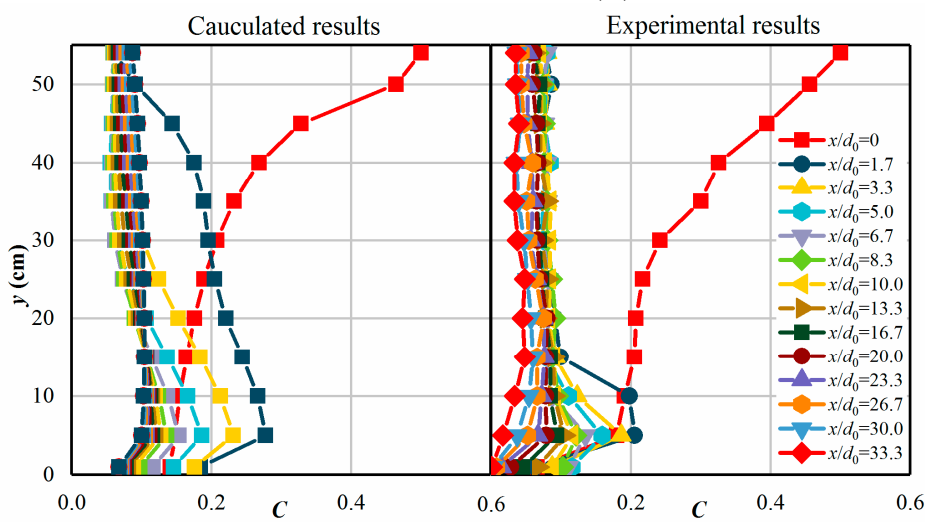

(e) $d_{0}=3 \mathrm{~cm}, C_{0}=50 \%, Q_{\mathrm{w}}=23.9 \mathrm{~L} / \mathrm{s}$

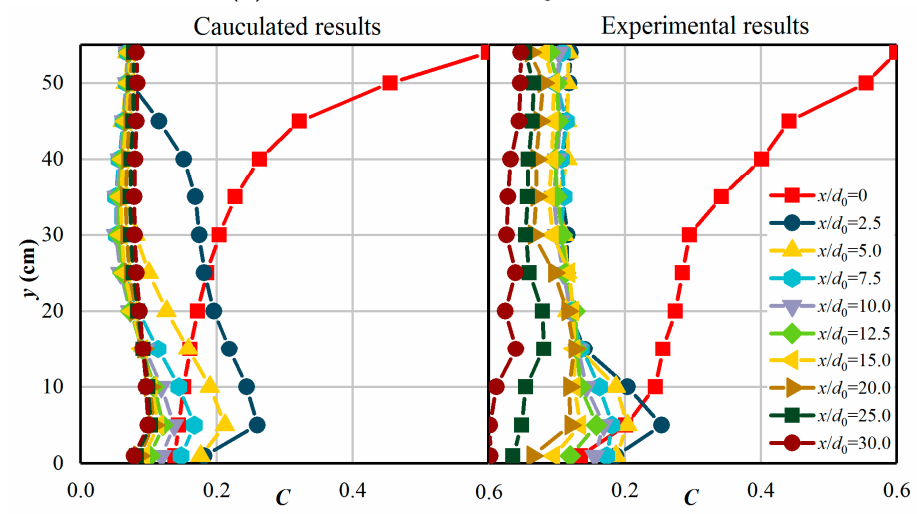

(f) $d_{0}=2 \mathrm{~cm}, C_{0}=60 \%, Q_{\mathrm{w}}=14.5 \mathrm{~L} / \mathrm{s}$

Figure 9. Comparison of calculated and experimental results. 


\section{Conclusions}

In this paper, a series of experimental studies on the air concentration distribution of vertical submerged aerated jet flows in a plunge pool were carried out. Based on the distribution law of the air concentration attenuation along the axial and lateral directions, an analysis model of the air concentration distribution in the plunge pool was proposed. The conclusions were as follows.

In the free jet region, the axial air concentration attenuation followed a power-law distribution, and the air concentration distribution along the lateral cross-sections conformed to the Gaussian distribution law. Both the axial attenuation and the lateral distribution of air concentration in the free jet region were almost unchanged for different initial water velocities, air concentrations, and flow rate conditions. Based on the observation and analysis of the flow patterns in the swirling region in the plunge pool, the air concentration was assumed to be a superposition of lateral diffusion in three stages of the jet flow. The position of the maximum air concentration values along the vertical cross-sections in the wall jet and the length of the swirling region, as well as their relationship with the initial flow conditions, were introduced. A set of formulas was proposed for the prediction of the air concentration distribution in the plunge pool. The present analysis model, the results of which have been compared with experimental data, can essentially predict the air concentration distribution of aerated jet flows in the swirling region of a plunge pool.

In water conservancy projects, the jet flows are aerated, and they form an air concentration distribution inside the plunge pool, which has a significant effect on the downstream energy dissipation and the total dissolved gas. Meanwhile, the increase in aeration results in changes to the mass and heat transfer process at the air-water interface. This research improves our understanding of the air dissolution process downstream practical applications, and provides a new model to predict the air concentration distribution in plunge pools caused by aerated jets. The results of this study reveal the complexity of the air concentration distribution in a plunge pool caused by aerated jets. In order to further improve the prediction accuracy for the air concentration distribution in plunge pools, coupling analyses of bubble floating by buoyancy and jet motion in the air diffusion process should be the focus of future studies.

Author Contributions: The paper is the product of the joint efforts of the authors who worked together on experimental model tests. W.X. conceived the experiments, having a scientific background in applied hydraulics. C.C. and W.W. conducted the experimental investigations and analyzed the data under the supervision of W.X. C.C. wrote the manuscript with the co-authors.

Funding: Resources to cover the Article Processing Charge were provided by the National Natural Science Foundation of China (Grant No. 51609162).

Conflicts of Interest: The authors declare no conflict of interest.

\section{References}

1. Beltaos, S.; Rajaratnam, N. Impinging Circular Turbulent Jets. J. Hydraul. Div. 1974, 100, 1313-1328.

2. Beltaos, S.; Rajaratnam, N. Impingement of Axisymmetric Developing Jets. J. Hydraul. Res. 2010, 15, 311-326. [CrossRef]

3. Cooper, D.; Jackson, D.C.; Launder, B.E.; Liao, G.X. Impinging jet studies for turbulence model assessment-I. Flow-field experiments. Int. J. Heat Mass Transfer 1993, 36, 2675-2684. [CrossRef]

4. Baydar, E.; Ozmen, Y. An experimental investigation on flow structures of confined and unconfined impinging air jets. J. Heat Mass Transfer 2006, 42, 338-346. [CrossRef]

5. Schmocker, L.; Pfister, M.; Hager, W.H.; Minor, H.E. Aeration characteristics of ski jump jets. J. Hydral. Eng. 2008, 98, 90-97. [CrossRef]

6. Ervine, D.A.; Falvey, H.T. Behaviour of turbulent water jets in the atmosphere and in plunge pools. Proc. Inst. Civil Eng. 1987, 83, 295-314. [CrossRef]

7. Ervine, D.A.; Falvey, H.T.; Withers, W. Pressure fluctuations on plunge pool floors. J. Hydraul. Res. 1997, 35, 257-279. [CrossRef] 
8. Castillo, L.G.; Carrillo, J.M.; Blázquez, A. Plunge pool dynamic pressures: A temporal analysis in the nappe flow case. J. Hydraul. Res. 2015, 53, 101-118. [CrossRef]

9. Chanson, H.; Aoki, S.; Hoque, A. Physical modelling and similitude of air bubble entrainment at vertical circular plunging jets. Chem. Eng. Sci. 2004, 59, 747-758. [CrossRef]

10. Wei, W.R.; Deng, J.; Liu, B. Influence of aeration and initial water thickness on axial velocity attenuation of jet flows. J. Zhejiang Univ-Sci. A (Appl Phys \& Eng). 2013, 14, 362-370. [CrossRef]

11. Wei, W.R.; Deng, J.; Liu, B.; Zhang, Y.L.; Qian, X.Y.; Liu, X.J. Experimental investigation on the effects of aeration on the velocity attenuation of jet flow. J. Sichuan Uni. 2011, 43, 29-33. [CrossRef]

12. Luo, M.; Guo, Y.K. Study of diffusion of confined two-dimensional aerated jets under water surface. J. Hydral. Eng. 1992, 7, 29-34. [CrossRef]

13. Melo, J. Reduction of plunge pool floor dynamic pressure due to jet air entrainment. In Proceedings of the International Workshop on Rock Scour due to Falling High-Velocity Jet, Lausanne, Switzerland, 25-28 September 2002; Schleiss, A.J., Bollaert, E.F., Eds.; Swets and Zei tlinger: Lisse, The Netherlands, 2002; pp. 125-136.

14. Deng, J.; Xu, W.L.; Liu, S.J.; Wang, W. Influence of water jet aeration on pressure in scour pool and plunge pool. Adv. Water Sci. 2009, 20,373-378. [CrossRef]

15. Xu, W.; Deng, J.; Qu, J.; Liu, S.; Wang, W. Experimental investigation on influence of aeration on plane jet scour. J. Hydral. Eng. 2004, 130, 160-164. [CrossRef]

16. Duarte, R.; Schleiss, A.J.; Pinheiro, A. Influence of jet aeration on pressures around a block embedded in a plunge pool bottom. Environ. Fluid Mech. 2015, 15, 673-693. [CrossRef]

17. Duarte, R.; Pinheiro, A.; Schleiss, A.J. An Enhanced Physically Based Scour Model for Considering Jet Air Entrainment. Eng. 2016, 2, 294-301. [CrossRef]

18. Sarkar, A.; Dey, S. Review on Local Scour Due to Jets. Int. J. Sediment. Res. 2004, 19, 53-81.

19. Pagliara, S.; Hager, W.; Minor, H.-E. Hydraulics of Plane Plunge Pool Scour. J. Hydral. Eng. 2006, 132, 450-461. [CrossRef]

20. Bollaert, E.; Schleiss, A. Scour of rock due to the impact of plunging high velocity jets Part II: Experimental results of dynamic pressures at pool bottoms and in one- and two-dimensional closed end rock joints. J. Hydraul. Res. 2003, 41, 465-480. [CrossRef]

21. Bin, A.K. Gas entrainment by plunging liquid jets. Chem. Eng. Sci 1993, 48, 136. [CrossRef]

22. Chanson, H. References. In Air Bubble Entrainment in Free-Surface Turbulent Shear Flows; Chanson, H., Ed.; Academic Press: San Diego, CA, USA, 1996; pp. 239-261. ISBN 978-0-12-168110-4.

23. Harby, K.; Chiva, S.; Muñoz-Cobo, J.L. An experimental study on bubble entrainment and flow characteristics of vertical plunging water jets. Exp. Therm. Fluid Sci. 2014, 57, 207-220. [CrossRef]

24. Brattberg, T.; Chanson, H. Air entrapment and air bubble dispersion at two-dimensional plunging water jets. Chem. Eng. Sci 1998, 53, 4113-4127. [CrossRef]

25. Kiger, K.T.; Duncan, J.H. Air-Entrainment Mechanisms in Plunging Jets and Breaking Waves. Annu. Rev. Fluid Mech. 2011, 44, 563-596. [CrossRef]

26. Miwa, S.; Moribe, T.; Tsutstumi, K.; Hibiki, T. Experimental Investigation of Air Entrainment by Vertical Plunging Liquid Jet. Chem. Eng. Sci 2018, 181. [CrossRef]

27. Brouilliot, D.; Lubin, P. Numerical simulations of air entrainment in a plunging jet of liquid. J. Fluids Struct. 2013, 43, 428-440. [CrossRef]

28. Samanta, A.; Vinuesa, R.; Lashgari, I.; Schlatter, P.; Brandt, L. Enhanced secondary motion of the turbulent flow through a porous square duct. J. Fluid Mech. 2015, 784, 681-693. [CrossRef]

29. Dong, Z.Y.; Wu, C.G. Characteristics of concentration diffusion of submerged aerated jets. J. Chengdu Univ. Sci. Technol. 1994, 4, 31-38.

30. Chanson, H. Air entrainment in two-dimensional turbulent shear flows with partially developed inflow conditions. Int. J. Multiphase Flow 1995, 21, 1107-1121. [CrossRef]

31. Khaled, J.H. Liquid Jet Impingement on a Free Liquid Surface: PIV Study of the Turbulent Bubbly Two-Phase Flow. In Proceedings of the ASME 2010 Joint Us-European Fluids Engineering Summer Meeting Collocated with International Conference on Nanochannels, Microchannels, and Minichannels ASME 2010 Joint Us-European Fluids Engineering Summer Meeting: Volume 1, Symposia-Parts A, B, and C, Montreal, QC, Canada, 1-5 August 2010; pp. 2877-2885. 
32. Vinuesa, R.; Schlatter, P.; Nagib, H.M. Role of data uncertainties in identifying the logarithmic region of turbulent boundary layers. Exp. Fluids 2014, 55, 1751. [CrossRef]

33. Albertson, M.L.; Dai, Y.B.; Jensen, R.A.; Rouse, H. Diffusion of Submerged Jets. Trans. Amer. Soc. Civil Eng. 1950, 115, 639-664. [CrossRef]

34. Prandtl, L. Bemerkungen zur Theorie der freien Turbulenz. Z.A.M.M. 1942, 22, 241-243. [CrossRef]

35. Beltaos, S.; Rajaratnam, N. Plane Turbulent Impinging Jet. J. Hydraul. Res. 1973, 11, 29-59. [CrossRef] 